\title{
Factors Influencing Decision-Making of Terminally III Cancer Patients and Their Families Regarding Where to Stay and Receive Final-Month Care: A Preliminary Study
}

Hayashi Eriko ( $\nabla$ eieritn@yahoo.co.jp )

Yokohama City University: Yokohama Shiritsu Daigaku https://orcid.org/0000-0002-4875-7024

Fukano Fumiyasu

Fujisawa Shounandai Hospital

Onishi Hideki

Saitama Medical University International Medical Center

Short report

Keywords: place for end-of-life care, place for final-month care, end of life, terminal cancer, caregiver burden, palliative care ward

Posted Date: August 3rd, 2021

DOI: https://doi.org/10.21203/rs.3.rs-754311/v1

License: (c) (1) This work is licensed under a Creative Commons Attribution 4.0 International License.

Read Full License 


\section{Abstract}

Background:

Advance care planning is essential for a better terminal phase, although many patients do not make a choice regarding the place of receiving terminal care even one month before the expected end of life. This study explores the factors that influence patients with a life-expectancy of less than one month when they are admitted to the palliative care ward or other terminal care institutions.

Methods:

Self-administered questionnaire surveys were completed by patients and caregiver questionnaire surveys were completed by patients and caregivers. We assessed patient symptoms using Support Team Assessment Schedule-Japan (STAS-J), and all patients' families answered the self-reported questionnaire, Caregiver Reaction Assessment-Japan (CRA-J).

Results:

The family care burden score for "Impact on schedule" was significantly higher for the palliative care ward inpatient group than for the non-inpatient group $(21.0 \pm 1.5 \mathrm{vs} .17 .6 \pm 1.8 ; \rho<0.01)$.

\section{Conclusions:}

Family burden might influence the choice of facility when patients with a survival prognosis of less than one month are admitted to the palliative care ward for reducing the burden of long-term care. Nurses should take care of family caregiver's physical and psychosocial health, especially before the patient's admission to the palliative care ward. The results of this study show that caregiver support is needed to reduce the feeling of family burden related to impact on schedule, enabling them to choose the best place for terminal care.

\section{Introduction}

Developments in medicine mean that it is now possible to continue anticancer treatment even after recurrence and metastasis. However, as treatment becomes difficult, the issue of the end-of-life (EOL) care place arises [1]. As terminally ill cancer patients develop cancer-specific physical symptoms, such as pain and fatigue, caregivers develop symptoms due to the psychological and physical burden of care, and the burden of medical expenses [2-5].

A survey of cancer patients' intent regarding medical treatment and place of death revealed that patients in Europe and the United States prefer to die at home, while patients in Asia, including Japan, tend to prefer the hospital [6]. Although studies have been conducted on factors related to decision-making regarding the place of EOL for the final month, most of them were retrospective surveys of bereaved families of cancer patients [6-8]. Hence, the factors influencing terminally ill cancer patients and their 
families in terms of the choice of care place by the families of EOL cancer patients with a life-expectancy of less than one month have not been fully clarified.

We report a preliminary survey regarding the factors affecting terminally ill cancer patients with a lifeexpectancy of less than one month and their caregivers when it is time to make a decision regarding a place to provide final-month care for EOL cancer patients. Although advance care planning (ACP) is essential for a smoother terminal phase, there are patients who have not made a choice regarding the place of receiving terminal care even one month before death. This preliminary survey was conducted among such cancer patients and their families. The study explores the factors that influence patients with a prognosis of less than one month when they make the decision to be admitted to a palliative care ward or other terminal care facility.

\section{Methods}

Subjects

Participants consisted of the caregiving family member and each of 14 cancer patients who had a lifeexpectancy of less than one month as diagnosed by a physician, who consulted with a cancer nursing specialist at the Cancer Nursing Consultation Department of Fujisawa Shounandai Hospital from June to September 2014. Primary physicians identified potential study participants according to the following criteria: (1) terminally ill cancer patients with a life-expectancy of less than one month, (2) age $\geq 20$ years for both patients and care-giving family members, and (3) cancer patients who had not decided where to stay and receive the final month EOL care. Exclusion criteria were lack of consent and a life-expectancy prognosis of more than one month. Terminally ill cancer patients and their families visited the nurse for a consultation about the impending distress and for decision-making related to the place for receiving finalmonth care.

Ethical considerations

This study was approved by the Institutional Review Board of Fujisawa Shounandai Hospital (28 - 004). Written informed consent was obtained from all participants prior to their enrollment in the study.

Survey method

A self-administered questionnaire survey was conducted.

Parameters assessed

1) Patient attributes

1. The patients' sex, age, cancer origin, time from first diagnosis (months), performance status (PS), place of medical treatment (outpatient, inpatient), pain management, understanding of medical 
condition (disease name, prognosis), mobility care assistance, mental state (anxiety/delirium, clarity) and pain, cognitive decline, insomnia, history of falls, and dementia were assessed.

2. The previously translated and validated Japanese symptom version of the Support Team Assessment Schedule (STAS), developed by Higginson et al., was used to measure the effect of symptoms on the patient [9].

3. The participants were dichotomized based on whether or not they were admitted to a palliative care ward and were classified as "palliative care ward" and "others".

2) Family attributes

The previously validated Japanese version of the Caregiver Reaction Assessment [4] scale developed by Given et al. was used to measure the care burden on family caregivers [10]. The caregivers' sex and age, relationship with the patient, and whether living together or apart was evaluated.

Analysis

Patients were divided into two groups according to where the patients actually stayed after they consulted the nurses and after the survey. The inpatient group included those admitted to the palliative care ward, and the non-inpatient group included patients who received care elsewhere, and their backgrounds and details of medical treatment were examined and compared. For statistical analysis, one-way analysis of variance and the unpaired t-test were used for continuous and ordinal variables, and Fisher's exact test was used for nominal variables, with the significance level set at $<5 \%$. All analyses were performed using JMP ver. 15 (SAS Institute).

\section{Results}

1) Overview of the patients and caregivers

Table 1 shows an overview of the patients. Consultations regarding medical treatments for terminally ill cancer patients with a survival prognosis of less than 1 month revealed that nine of them decided to receive care in the palliative care ward and were admitted within a week. The other five patients decided to receive care elsewhere, and patients who were hospitalized at the time of the survey were discharged to their homes within 3 days. Ten of the patients were male (71.4\%), with an average age of $75.0 \pm 6.5$ years. Cancer type was gastric in two (14.3\%), and lung cancer in three (21.4\%) patients, with a PS of 3 or higher in seven patients $(50.0 \%)$. Opioids were used by eight patients (57.1\%). Total STAS-J scores were not significantly different between palliative and non-palliative care ward patients $(20.3 \pm 9.7$ and $19.8 \pm 5.2$ respectively, $p=0.91$ ). 
Table 1

Patients' attributes

\begin{tabular}{|c|c|c|c|c|}
\hline & $\begin{array}{l}\text { Overall } \\
n=14\end{array}$ & $\begin{array}{l}\text { Palliative care ward } n \\
=9\end{array}$ & $\begin{array}{l}\text { Others } \\
n=5\end{array}$ & $\begin{array}{l}\text { p- } \\
\text { value }\end{array}$ \\
\hline Patient sex & & & & 0.22 \\
\hline Female & 4 & 4 & 0 & \\
\hline Male & 10 & 5 & 5 & \\
\hline Patient age (years) & & & & $0.41^{\dagger}$ \\
\hline Mean \pm standard deviation & $\begin{array}{l}75.0 \pm \\
6.47\end{array}$ & $73.9 \pm 7.7$ & $77.0 \pm 3.1$ & \\
\hline Cancer origin & & & & 0.76 \\
\hline Gastric cancer & 2 & 1 & 1 & \\
\hline Lung cancer & 3 & 1 & 2 & \\
\hline Colorectal cancer & 2 & 2 & & \\
\hline Pancreatic cancer & 2 & 2 & & \\
\hline Breast cancer & 1 & 1 & & \\
\hline Liver cancer & 1 & 1 & & \\
\hline Kidney cancer & 1 & & 1 & \\
\hline Prostate cancer & 2 & 1 & 1 & \\
\hline $\begin{array}{l}\text { Time from the first diagnosis } \\
\text { (months) }\end{array}$ & & & & $0.54^{\dagger}$ \\
\hline Mean \pm standard deviation & $\begin{array}{l}17.4 \pm \\
17.5\end{array}$ & $15.1 \pm 12.2$ & $\begin{array}{l}21.4 \pm \\
25.8\end{array}$ & \\
\hline PS & & & & 0.83 \\
\hline 0 & 1 & 1 & & \\
\hline 1 & 2 & 1 & 1 & \\
\hline 2 & 4 & 2 & 2 & \\
\hline 3 & 6 & 4 & 2 & \\
\hline 4 & 1 & 1 & & \\
\hline Place of medical treatment & & & & 1.00 \\
\hline Hospitalization & 7 & 4 & 3 & \\
\hline
\end{tabular}




\begin{tabular}{|c|c|c|c|c|}
\hline & $\begin{array}{l}\text { Overall } \\
n=14\end{array}$ & $\begin{array}{l}\text { Palliative care ward } n \\
=9\end{array}$ & $\begin{array}{l}\text { Others } \\
n=5\end{array}$ & $\begin{array}{l}\mathrm{p} \text { - } \\
\text { value }\end{array}$ \\
\hline Outpatient & 7 & 5 & 2 & \\
\hline Pain treatment & & & & 0.58 \\
\hline Opioids & 8 & 6 & 2 & \\
\hline None & 6 & 3 & 3 & \\
\hline $\begin{array}{l}\text { Understanding of medical } \\
\text { condition }\end{array}$ & & & & 0.31 \\
\hline Disease name & 11 & 8 & 3 & \\
\hline Prognosis & 3 & 1 & 2 & \\
\hline Mobility assistance & & & & 0.27 \\
\hline Assistance needed & 7 & 6 & 1 & \\
\hline Able to walk & 7 & 3 & 4 & \\
\hline Mental state & & & & 1.00 \\
\hline Anxiety/delirium & 8 & 5 & 3 & \\
\hline No clarity issues & 6 & 4 & 2 & \\
\hline Pain & & & & 0.51 \\
\hline Yes & 11 & 8 & 3 & \\
\hline None & 3 & 1 & 2 & \\
\hline Cognitive decline & & & & 0.30 \\
\hline Yes & 6 & 5 & 1 & \\
\hline None & 8 & 4 & 4 & \\
\hline Insomnia & & & & 1.00 \\
\hline Yes & 9 & 6 & 3 & \\
\hline None & 5 & 3 & 2 & \\
\hline History of falls & & & & 1.00 \\
\hline Yes & 3 & 2 & 1 & \\
\hline None & 11 & 7 & 4 & \\
\hline Dementia & & & & 1.00 \\
\hline
\end{tabular}




\begin{tabular}{|lllll|}
\hline & $\begin{array}{l}\text { Overall } \\
\mathbf{n = 1 4}\end{array}$ & $\begin{array}{l}\text { Palliative care ward } \mathbf{n} \\
\mathbf{9}\end{array}$ & $\begin{array}{l}\text { Others } \\
\mathbf{n = 5}\end{array}$ & $\begin{array}{l}\text { p- } \\
\text { value }\end{array}$ \\
\hline Yes & 3 & 2 & 1 & \\
\hline None & 11 & 7 & 4 & $0.91^{\dagger}$ \\
\hline Total STAS-J score & $20.1 \pm 8.2$ & $20.3 \pm 9.7$ & $19.8 \pm 5.2$ & \\
\hline $\begin{array}{l}\text { Fisher's exact test, } \\
\text { +: Ordinal scale/continuous variables were assessed using one-way ANOVA, with } p<0.05 \text { considered } \\
\text { significant. } \\
\text { PS: performance status }\end{array}$ & & & \\
\hline
\end{tabular}

Table 2 shows data on the caregivers, 10 of whom were women $(71.4 \%)$, including four wives $(28.6 \%)$ and five daughters (35.7\%). The average caregiver age was $58.6 \pm 11.6$ years, and nine lived with the patient (64.3\%). At the time of the survey, there were seven outpatients and seven inpatients $(50.0 \%)$. 
Table 2

Family caregiver's attributes

\begin{tabular}{|c|c|c|c|c|}
\hline & $\begin{array}{l}\text { Overall } \\
n=14\end{array}$ & $\begin{array}{l}\text { Palliative care ward } n= \\
9\end{array}$ & $\begin{array}{l}\text { Others } \\
n=5\end{array}$ & p-value \\
\hline Caregiver sex & & & & 0.22 \\
\hline Female & 10 & 5 & 5 & \\
\hline Male & 4 & 4 & 0 & \\
\hline Caregiver age (years) & & & & $0.01^{\dagger} \star$ \\
\hline Mean \pm standard deviation & $\begin{array}{l}58.6 \pm \\
11.6\end{array}$ & $64.0 \pm 10.9$ & $\begin{array}{l}48.8 \pm \\
3.6\end{array}$ & \\
\hline $\begin{array}{l}\text { Caregiver's relationship with } \\
\text { patient }\end{array}$ & & & & $0.02^{\star}$ \\
\hline Wife & 4 & 4 & & \\
\hline Husband & 2 & 2 & & \\
\hline Son & 2 & 2 & & \\
\hline Daughter & 5 & 1 & 4 & \\
\hline Daughter-in-law & 1 & & 1 & \\
\hline Living together or apart & & & & $\dot{0.001 *}$ \\
\hline Together & 9 & 9 & 0 & \\
\hline Apart & 5 & 0 & 5 & \\
\hline \multicolumn{5}{|c|}{$\begin{array}{l}\text { Fisher's exact test, } \\
\text { †: Ordinal scale/continuous variables were assessed using one-way ANOVA, with } p<0.05 \text { considered } \\
\text { significant. }\end{array}$} \\
\hline \multicolumn{5}{|l|}{ PS: performance status } \\
\hline
\end{tabular}

2) Factors associated with family care burden and palliative care ward admission

Table 3 shows the relationship between the choice of care place and the burden on family caregivers. Regarding family care burden, the subject score for "Impact on schedule" was significantly higher in the inpatient than the non-inpatient group $(21.0 \pm 1.5 \mathrm{vs} .17 .6 \pm 1.8 ; \rho<0.01)$. No other significant correlations were observed. 
Table 3

Factors associated with family care burden and palliative care ward admission

\begin{tabular}{|lllll|}
\hline & $\begin{array}{l}\text { Overall } \\
\mathbf{n = 1 4}\end{array}$ & $\begin{array}{l}\text { Palliative care } \\
\text { ward } \mathbf{n = 9}\end{array}$ & $\begin{array}{l}\text { Others } \\
\mathbf{n = 5}\end{array}$ & p-value \\
\hline Mean \pm standard deviation & & & & \\
\hline Total CRF score & $52.9 \pm 8.4$ & $55.6 \pm 8.9$ & $48.0 \pm 4.9$ & 0.11 \\
\hline Impact on schedule (5-25) & $19.9 \pm 2.4$ & $21.0 \pm 1.5$ & $17.6 \pm 1.8$ & $<0.01^{*}$ \\
\hline Caregiver's self-esteem (5-25) & $11.0 \pm 3.4$ & $10.8 \pm 3.8$ & $11.4 \pm 3.0$ & 0.76 \\
\hline Lack of family support (4-20) & $9.9 \pm 3.1$ & $10.6 \pm 3.2$ & $8.8 \pm 2.9$ & 0.33 \\
\hline Impact on health (2-10) & $6.2 \pm 2.0$ & $6.9 \pm 2.0$ & $5.0 \pm 1.4$ & 0.09 \\
\hline Impact on finances (2-10) & $6.5 \pm 2.3$ & $7.0 \pm 2.6$ & $5.6 \pm 1.5$ & 0.30 \\
\hline *: $\mathbf{p}<0.05$ with one-way analysis of variance considered significant & \\
\hline
\end{tabular}

\section{Discussion}

In this study, we found that terminally ill cancer patients with a life-expectancy of less than one month whose families feel the care interferes with their schedules are more likely to be hospitalized in the palliative care ward. Worsening of symptoms in EOL patients does not affect decision-making regarding the final place of care, because total STAS-J score was not significantly different between palliative care ward admission and non-admission. In this study, the decision regarding admission to a palliative care ward tended to be made by older families and those who were living together. Terminally ill cancer patients develop physical symptoms peculiar to cancer, such as pain and fatigue, and caregivers experience a psychological, physical and financial burden related to medical expenses when providing care $[3-5,11-13]$. Nurses should take care of family caregiver's physical and psychosocial health, especially before the patient's admission to a palliative care ward [14]. The results of this study show that support is needed to reduce the sense of family burden related to impact on schedule, which would enable them to choose the best place for terminal care.

The situation where patients have not decided the place for receiving care even at the end of life might be related to the fact that very few explanations about impeding death are given to patients in Japan [15]. Few Japanese patients (4.8\%) were informed of their impending death. Some studies reported that when elderly people needed discussions for decision making near the end of life, most lacked the capacity to make decisions [15-19]. Health care professionals were viewed as playing an important role in addressing interventions to improve communication, and in discussions about decision-making regarding the goals of EOL care $[13,19-21]$. Nurses might need to provide assistance to families and physicians to facilitate EOL discussions for the entire family. 
This study has some limitations. The participants were limited to patients with EOL cancer and a less than one-month survival prognosis. Caregiver age correlates significantly with the location of terminal care (younger caregivers prefer non-palliative care ward care). In future, further studies involving larger populations based on multi-facility surveys are necessary.

\section{Conclusion}

Family burden might influence the decision regarding whether or not patients with a prognosis of less than one month are admitted to the palliative care ward for reducing the family caregiver's long-term care burden. Nurses should take care of the family caregiver's physical and psychosocial health, especially before the patient's admission to the palliative care ward. The results of this study show that support that reduces the feeling of family burden related to impact on schedule is needed to enable them to choose the best place for terminal care.

\section{Declarations}

\section{Ethics approval and consent to participate}

This study was approved by the Institutional Review Board of Fujisawa Shounandai Hospital (28-004). All subjects provided written informed consent to participate in the study.

\section{Consent for publication}

Written informed consent for publication of this report was obtained from all participants prior to their enrollment in the study.

\section{Availability of data and materials}

Detailed data are available from the corresponding author upon reasonable request.

\section{Competing interests}

The authors declare that they have no competing interests.

\section{Funding}

This research received no specific grant from any funding agency in the commercial or not-for-profit sectors.

\section{Authors' contributions}

$\mathrm{EH}$ and FF organized the study. Data collection was performed by EH and the institution's physician, who designed the methods and wrote the first draft of the manuscript. HO revised the draft of the manuscript. All authors approved the final version of the manuscript. 
Acknowledgements

The authors would like to thank the patients and their family members.

\section{Authors' information (optional)}

Eriko Hayashi, R.N., Ph.D. (Corresponding Author)

Nursing Course, School of Medicine, Yokohama City University

3-9 Fukuura, Kanazawa-ku, Yokohama, Kanagawa 236-0004, Japan

and Fujisawa Shounandai Hospital

2345 Takakura, Fujisawa-shi, Kanagawa 252-0802, Japan

TEL: +81-45-787-2554; Email: erieritn@yahoo.co.jp

Fumiyasu Fukano, M.D.

Palliative Care Ward Doctor,

Fujisawa Shounandai Hospital

2345 Takakura, Fujisawa-shi, Kanagawa 252-0802, Japan

Hideki Onishi ,MD, PhD

Department of Psycho-oncology,

Saitama Medical University International Medical Center

1397-1 Yamane, Hidaka City, Saitama 350-1298, Japan

\section{References}

1. Buiting HM, Rurup ML, Wijsbek $H$, van Zuylen $L$, den Hartogh $G$. Understanding provision of chemotherapy to patients with end stage cancer: qualitative interview study. BMJ 2011;342:d1933; doi: 10.1136/bmj.d1933.

2. Hui D, dos Santos R, Chisholm G, Bansal S, Silva TB, Kilgore K, et al. Clinical signs of impending death in cancer patients. Oncologist. 2014;19:681-7. doi:10.1634/theoncologist.2013-0457.

3. Grov EK, Fosså SD, Sørebø O, Dahl AA. Primary caregivers of cancer patients in the palliative phase: a path analysis of variables influencing their burden. Soc Sci Med. 2006;63:2429-39. doi:10.1016/j.socscimed.2006.06.008. 
4. Grunfeld E, Coyle D, Whelan T, Clinch J, Reyno L, Earle CC, et al. Family caregiver burden: results of a longitudinal study of breast cancer patients and their principal caregivers. CMAJ. 2004;170:1795801. doi:10.1503/cmaj.1031205.

5. Currow DC, Clark K, Kamal A, Collier A, Agar MR, Lovell MR, et al. The population burden of chronic symptoms that substantially predate the diagnosis of a life-limiting illness. J Palliat Med. 2015;18:480-5. doi:10.1089/jpm.2014.0444.

6. Yamagishi A, Morita T, Miyashita M, Yoshida S, Akizuki N, Shirahige Y, et al. Preferred place of care and place of death of the general public and cancer patients in Japan. Support Care Cancer. 2012;20:2575-82. doi:10.1007/s00520-011-1373-8.

7. Sato K, Miyashita M, Morita T, Tsuneto S, Shima Y. Family member perspectives of deceased relatives' end-of-life options on admission to a palliative care unit in Japan. Support Care Cancer. 2012;20:893-900. doi:10.1007/s00520-012-1405-z.

8. Nakamura S, Kuzuya M, Funaki Y, Matsui W, Ishiguro N. Factors influencing death at home in terminally ill cancer patients. Geriatr Gerontol Int. 2010;10:154-60. doi:10.1111/j.14470594.2009.00570.x.

9. Higginson IJ, McCarthy M. Validity of the support team assessment schedule: do staffs' ratings reflect those made by patients or their families? Pall Med. 1993;7:219-28. doi:10.1177/026921639300700309.

10. Misawa T, Miyashita M, Kawa M, Abe K, Abe M, Nakayama Y, et al. Validity and reliability of the Japanese version of the Caregiver Reaction Assessment Scale (CRA-J) for community-dwelling cancer patients. Am J Hosp Palliat Care. 2009;26:334-40. doi:10.1177/1049909109338480.

11. Murray MA, Fiset V, Young S, Kryworuchko J. Where the dying live: a systematic review of determinants of place of end-of-life cancer care. Oncol Nurs Forum. 2009;36:69-77. doi:https://doi.org/10.1188/09.0NF.69-77.

12. Hubbard G, Illingworth N, Rowa-Dewar N, Forbat L, Kearney N. Treatment decision-making in cancer care: the role of the carer. J Clin Nurs. 2010;19:2023-31. doi:https://doi.org/10.1111/j.13652702.2009.03062.x.

13. Huang HL, Chiu TY, Lee LT, Yao CA, Chen CY, Hu WY. Family experience with difficult decisions in endof-life care. Psychooncology. 2012;21:785-91. doi:https://doi.org/10.1002/pon.3107.

14. Edwards SB, Olson K, Koop PM, Northcott HC. Patient and family caregiver decision making in the context of advanced cancer. Cancer Nurs 2012;35:178 - 86; doi: https://doi.org/10.1097/NCC.0b013e31822786f6.

15. Yamaguchi T, Maeda I, Hatano Y, Suh SY, Cheng SY, Kim SH, et al, EASED investigators. Communication and behavior of palliative care physicians of patients with cancer near end of life in three east Asian countries. J Pain Symptom Manage 2021;61:315-22.e1; doi:10.1016/j.jpainsymman.2020.07.031.

16. Zaros MC, Curtis JR, Silveira MJ, Elmore JG. Opportunity lost: end-of-life discussions in cancer patients who die in the hospital. J Hosp Med. 2013;8:334-40. doi:10.1002/jhm.1989. 
17. Silveira MJ, Kim SY, Langa KM. Advance directives and outcomes of surrogate decision making before death. N Engl J Med. 2010;362:1211-8. doi:10.1056/NEJMsa0907901.

18. Tilburgs B, Vernooij-Dassen M, Koopmans R, van Gennip H, Engels Y, Perry M. Barriers and facilitators for GPs in dementia advance care planning: A systematic integrative review. PLOS ONE. 2018;13:e0198535. doi:10.1371/journal.pone.0198535.

19. Pardon K, Deschepper R, Vander Stichele R, Bernheim JL, Mortier F, Schallier D, et al. Preferred and actual involvement of advanced lung cancer patients and their families in end-of-life decision making: a multicenter study in 13 hospitals in Flanders, Belgium. J Pain Symptom Manage. 2012;43:515-26. doi:https://doi.org/10.1016/j.jpainsymman.2011.04.008.

20. You JJ, Downar J, Fowler RA, Lamontagne F, Ma IW, Jayaraman D, et al. Canadian Researchers at the End of Life Network. Barriers to goals of care discussions with seriously ill hospitalized patients and their families: a multicenter survey of clinicians. JAMA Intern Med. 2015;175:549-56. doi:10.1001/jamainternmed.2014.7732.

21. Brighton LJ, Bristowe K. Communication in palliative care: talking about the end of life, before the end of life. Postgrad Med J. 2016;92:466-70. doi:10.1136/postgradmedj-2015-133368. 